\title{
Cinema e espaço urbano (volume 2)
}

1.

Este dossiê que agora se apresenta pela Revista Rebeca, em seu $17^{\circ}$ número, Cinema e Espaço Urbano, surgiu a partir de uma iniciativa ancorada no projeto "O Cinema e o Mundo: Estudos Sobre Espaço e Cinema" (grupo de pesquisa vinculado ao Centro de Estudos Comparatistas - CEC - da Universidade de Lisboa, Portugal). Em seus encontros mensais, os diferentes membros residentes e os mais variados colaboradores em trânsito por Lisboa, passaram a discutir um modelo de colaboração que desse forma às linhas de investigação de cada um de seus participantes. Rapidamente deu-se conta de que a maioria dos pesquisadores era sensível a um tema comum (talvez por circunstâncias políticas cada vez mais evidentes, sendo ele central ou lateral aos objetos de investigação acadêmica em curso): o cinema e a sua relação com espaços urbanos. O impulso para organizar este dossiê foi, portanto, o de com ele propiciar um contexto de interseção para os variados tipos de análise sobre, ou a partir, de filmes que afloram essa relação, embora ancorando a perspectiva da teorização no conceito de espaço fílmico - o qual leva em conta a análise de como o tempo, a cultura e a sociedade são "espacializados" na criação de imagens em movimento.

O interesse manifestado pela Revista Rebeca ao projeto de publicação apresentado foi a oportunidade que os integrantes do CEC buscavam para fazer nascer, agora com bases sólidas em uma revista de ampla circulação, um projeto há muito almejado. Além disso, a Revista Rebeca possibilitou que o propósito originalmente situado naquele grupo de pesquisa ganhasse maior envergadura e a inclusão de novos autoras e autores da mais elevada competência.

Diante desse processo em retrospectiva, seria oportuno o questionamento: por qual razão devemos associar o cinema e a cidade como temas comuns, se tal temática apresenta mais linhas de fuga divergentes do que modelos de confluência teórica?

A resposta implica voltarmos às raízes históricas da qual somos herdeiros. É sabido que o cinema - desde as suas origens até a contemporaneidade, nas suas mais diversas manifestações - colhe da vida urbana alguns dos seus conteúdos capitais. Modelos inequívocos de tal reciprocidade são os filmes que, entre as primeiras cityscapes dos irmãos Lumière e as mais variadas formas de expressão nas cinematografias contemporâneas em todo o mundo, continuam a provocar uma urgente reflexão sobre percepções coletivas, momentos históricos precisos e mudanças sutis (ou traumáticas) sofridas por determinadas instâncias. Pensar o cinema e a cidade através da sua sempre contemporânea relação - ou que a partir dela se produz - sempre foi, e ainda é, por tudo isso, uma ótima maneira para se repensar os fenômenos da vida 
urbana que a todos afetam de forma cada vez mais global. A imagem daqueles que, física e politicamente, desses centros urbanos são expulsos, ou que para eles inevitavelmente se encaminham sem recursos, tal como genialmente profetizado no primeiro e último planos de Vidas Secas (Nelson Pereira dos Santos, 1964), tem hoje um sentido cristalino: como a família do filme, estamos todos cada vez mais à deriva, subalternizados pelas condições socioeconômicas, algures entre a cidade e toda a estética da fome que dela, qual epicentro do poder neoliberal, emana centrifugamente em seu redor.

Como tal, a hipótese fundamental a se explorar neste dossiê é se o cinema e as suas formas podem funcionar como operação de ressignificação através da percepção sobre gestos e práticas que as narrativas (dos filmes) nos permitem engendrar no cotidiano. Na rede de ideias que se pretendeu tecer, confiamos na hipótese de que a relação entre os vários filmes e seus espaços analisados possa ser traduzida em futuros exercícios coletivos de reflexão, discussão, documentação e ação politizada, que cabem naturalmente às leitoras e aos leitores prosseguir em diferentes tipos de contexto.

2.

Convém salientar que acreditamos estar perto de um ponto de necessária suspensão face a tantas questões já levantadas - mas também de outras ainda possíveis de levantar -, no qual a vontade de dar respostas concretas suscita mais problemas teóricos que soluções práticas. Como tal, adverte-se que as respostas para tais problemas que aqui se apresentam, partindo de uma atenta leitura dos filmes analisados, apontam para questões sine quo non que qualquer avaliador(a) deve reter durante a leitura dos textos e após a mesma:

1) $O$ que significa pensar a cidade e as suas mutações sociopolíticas no contexto cinematográfico e cinemático atual?

2) De que maneira interferem as formas dos filmes na vida de todos os dias, no atual contexto em que as cidades e o os espaços fílmicos se complementam enquanto formas do cotidiano?

3) Como podem as práticas e formas de relação nos espaços fílmicos servirem de ferramenta, lente ou recurso alternativo para ressignificar ética, política e esteticamente as práticas do cotidiano - do mais moribundo ao mais fulgurante - no século XXI?

Os artigos presentes neste dossiê não pretendem responder frontalmente a tais questões, mas a recorrente intersecionalidade dos argumentos esboça indiretamente uma linha de compreensão ativa das mesmas. Tais artigos devem, como tal, ser vistos 
como lanternas que iluminam um caminho no qual as relações entre teoria, cultura e sociedade se intensificam sob o imperativo do pensar cinematográfico.

Esta metodologia intersecional não pretende eludir, no entanto, um dos escolhos mais salientes do percurso que aqui, neste dossiê, se enfrenta. Falamos natural e novamente de um dos tópicos mais debatidos e rebatidos dos estudos fílmicos, que sempre foi o da relação entre cinema e cidade. Esse tópico sempre foi ele mesmo uma interseção na qual tanto confluem como a partir dela deflagram campos de saber tão apelativos como complexos de relacionar. Sejamos otimistas, então, e acreditemos que as relações que os estudos fílmicos procuram aqui estabelecer entre cinema e cidade são uma ótima demonstração do caminho que ainda há que se fazer entre as humanidades, as ciências e os estudos culturais. Nos filmes analisados encontramos em comum a vontade de dar respostas a essa necessidade, partindo do pressuposto de que, apesar de já muito ter sido feito, ainda mais há a fazer.

Se, como disse Walter Benjamin, Paris foi a capital do século XIX e o cinema a do século $\mathrm{XX}$, então esta iniciativa conjunta ilustra a vontade de, através dos filmes, acompanharmos criticamente um movimento inverso que já está em curso nas cidades de que estamos a ser expulsos, ou pior, nas quais somos obrigados a viver em condições cada vez mais degradantes, no mínimo desiguais. Talvez os dois volumes do dossiê Cinema e Espaço Urbano possam inspirar uma forma de estar nas cidades para as quais, no futuro, nos teremos necessariamente de encaminhar e reinventar. Essa é a mesma coragem que os seus autores tiveram em demorar-se nos filmes de que escolheram falar, como que teimando em levar a cabo uma contemplação profunda de objetos móveis, cintilantes, em pleno centro da cidade imparável e cada vez mais feroz que é o meio acadêmico. Reconheçamos a coragem de, em pleno "horário de pico", olhar atentamente para os filmes e para os seus espaços, no sentido de (com eles se) construir um possível ângulo de observação que permita delinear e compilar os problemas essenciais que nos espaços urbanos se têm vindo a adensar desde a segunda metade do século anterior.

3.

Como na vida na cidade, só no recolhimento posterior de um qualquer abrigo seguro se poderá realmente sentir o impacto indireto do movimento que as coisas imprimem em nós. Esse recolhimento é aqui concebido na forma de pensamento. Acima de tudo, as linhas de partida e chegada deste dossiê convocam uma disposição política para conferir vitalidade a esse pensar. Com isto não nos referimos a tomadas de posição vincadas ou ideologicamente assumidas. Antes, falamos de uma capacidade e vontade de elaborar uma abertura teórica nos próprios textos: que neles se possam estabelecer 
pontos de contato não só com a habitual comunidade acadêmica em que comumente circulam, mas também com o mundo da vida. Que cada texto suscite nas leitoras e nos leitores a necessidade de ser artista no palco dramático que os envolve; que, na pior das hipóteses, a seleção de textos que se teceu deixe leitoras e leitores sensíveis às várias nuances táticas e estratégicas que os envolvem nas novas movimentações urbanas e nas mais recentes redes de sociabilidade.

Por fim, o dossiê Cinema e Espaço Urbano é composto por dois volumes, que se apresentam em seções reflexivas específicas:

\section{Os Espaços dos Filmes (volume 1)}

- "Paisagens vividas, trabalhadas, truncadas. Iconografia da periferia urbana no cinema ibérico da austeridade" (Iván Villarmea Álvarez);

- "A cidade depois: sobre Detropia" (José Duarte);

- "Superstar e Safe de Todd Haynes: espaços femininos subversivos" (Bárbara Paiva Correia de Vallera);

- "A estratificação social na América Latina representada nos espaços domésticos e simbólicos: uma análise comparativa dos filmes Que Horas Ela Volta? e Roma" (Tatiana Martins Montenegro e Rogério de Souza Sérgio Ferreira);

- "Representações da vida cotidiana do Recife no cinema de Kleber Mendonça Filho" (Paula Gonçalves da Silva e Sérgio Carvalho Benício de Mello);

- "Poéticas e signos alegóricos em O Som ao Redor" (Wendell Marcel Alves da Costa);

- "Para uma leitura do espaço em João César Monteiro" (Pedro Camacho Costa);

- O cinema e a cidade no Portugal europeu (Mariana Liz [tradução]).

\section{Os Espaços da Imagem (volume 2)}

- "Uma sinfonia silenciosa: a cidade contemporânea segundo Harun Farocki" (Luís Flores e César Guimarães);

- "Memória cultural e o espaço (re)imaginado em Hóspedes da Noite, de Licínio Azevedo" (Tiago Vieira e Isabel Macedo);

- "Telas migrantes: uma geografia urbana das salas de exibição comercial no Brasil do século XXI" (Renata Rogowski Pozzo);

- "Curadoria e cinefilia em salas universitárias: o Cine UFPel e o cinema brasileiro" (Maurício Vassali e Ivonete Pinto); 
- "Mulheres na Cinemateca do Museu Guido Viaro" (Ana Claudia Camila Veiga de França e Ronaldo de Oliveira Corrêa);

- "Releituras de Gilberto Freyre pelo cinema brasileiro" (Vitor Zan);

- "Realismo contemporâneo: a estética do fluxo e o presenteísmo" (Marília Xavier de Lima e Lúcio Reis Filho);

- "Imagem-Espaço" (Diogo Cavalanti Velasco).

\section{NOTA:}

O dossiê temático Cinema e Espaço Urbano fora projetado, e avançou com suas iniciativas preliminares de elaboração, meses antes que a pandemia de Covid-19, doença causada pelo novo Coronavírus (denominado SARS-CoV-2) se espalhasse por todo o mundo.

Tratando-se de um acontecimento histórico ainda sem conceituação delimitada, é fato que o lançamento do volume 2 de Cinema e Espaço Urbano se dá em meio a um momento de excepcionalidade sustentado pela tragédia de centenas de milhares de mortes em todo o mundo, estando o Brasil (no momento em que esta nota é escrita) na triste e lamentável segunda posição dos países mais afetados por mortes provocadas por tal doença (atrás apenas dos EUA).

Que a pandemia de Covid-19 implique sobre as mais variadas articulações de vida (individual e coletivamente) que se seguirão daqui para frente, nomeadamente em razão dos procedimentos de isolamento social e de reavaliação dos mecanismos de ocupação do espaço público nas cidades, é uma conclusão absolutamente legítima. Articulações sobre as quais as narrativas e as estéticas cinematográficas futuras certamente muito terão a acrescentar.

Nesse âmbito, acreditamos ser equivocado supor que a relação "cinema-espaço urbano" não seja tema de aprofundamentos reflexivos a posteriori. Que isso sugira qualquer desatualização e/ou desautorização relativamente às investigações presentes nos artigos deste dossiê, não cremos ser o caso. Na verdade, tanto antes: fruto de um processo iniciado previamente e finalizado posteriormente à pandemia de Covid-19, Cinema e Espaço Urbano passa a sugerir, de fato, uma ressignificação dos pontos de vista colocados em causa; convocando, portanto, um debate em continuidade permanente, com vistas àquilo que (mais do nunca) o inesperado futuro nos reserva.

Wiliam Pianco (FMU - FIAM FAAM, Brasil; Universidade do Algarve, Portugal), Pedro Florêncio (Universidade de Lisboa). 